\title{
Significance of uncoupling protein 3 in mitochondrial function upon mid- and long-term dietary high-fat exposure
}

Citation for published version (APA):

Nabben, M., Hoeks, J., Kornips, C. F. P., Van Beurden, D., Briedé, J. J., Hesselink, M. K. C., Glatz, J. F., \& Schrauwen, P. (2011). Significance of uncoupling protein 3 in mitochondrial function upon mid- and long-term dietary high-fat exposure. Febs Letters, 585(24), 4010-4017.

https://doi.org/10.1016/j.febslet.2011.11.012

Document status and date:

Published: 15/12/2011

DOI:

10.1016/j.febslet.2011.11.012

Document Version:

Publisher's PDF, also known as Version of record

Document license:

Taverne

Please check the document version of this publication:

- A submitted manuscript is the version of the article upon submission and before peer-review. There can be important differences between the submitted version and the official published version of record.

People interested in the research are advised to contact the author for the final version of the publication, or visit the DOI to the publisher's website.

- The final author version and the galley proof are versions of the publication after peer review.

- The final published version features the final layout of the paper including the volume, issue and page numbers.

Link to publication

\footnotetext{
General rights rights.

- You may freely distribute the URL identifying the publication in the public portal. please follow below link for the End User Agreement:

www.umlib.nl/taverne-license

Take down policy

If you believe that this document breaches copyright please contact us at:

repository@maastrichtuniversity.nl

providing details and we will investigate your claim.
}

Copyright and moral rights for the publications made accessible in the public portal are retained by the authors and/or other copyright owners and it is a condition of accessing publications that users recognise and abide by the legal requirements associated with these

- Users may download and print one copy of any publication from the public portal for the purpose of private study or research.

- You may not further distribute the material or use it for any profit-making activity or commercial gain

If the publication is distributed under the terms of Article $25 \mathrm{fa}$ of the Dutch Copyright Act, indicated by the "Taverne" license above, 


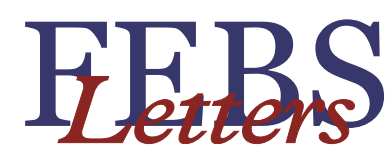

journal homepage: www.FEBSLetters.org

\title{
Significance of uncoupling protein 3 in mitochondrial function upon mid- and long-term dietary high-fat exposure
}

\author{
Miranda Nabben ${ }^{a}$, Joris Hoeks ${ }^{a}$, Esther Moonen-Kornips ${ }^{a}$, Denis van Beurden ${ }^{a}$, Jacob J. Briedé ${ }^{c}$, \\ Matthijs K.C. Hesselink ${ }^{\text {b }}$, Jan F.C. Glatz ${ }^{\mathrm{d}}$, Patrick Schrauwen ${ }^{\mathrm{a}, *}$ \\ a Departments of Human Biology, NUTRIM School for Nutrition, Toxicology and Metabolism, Maastricht University Medical Center+, Maastricht, The Netherlands \\ ${ }^{\mathrm{b}}$ Human Movement Sciences, NUTRIM School for Nutrition, Toxicology and Metabolism, Maastricht University Medical Center+, Maastricht, The Netherlands \\ ${ }^{\mathrm{c}}$ Health Risk Analysis and Toxicology, NUTRIM School for Nutrition, Toxicology and Metabolism, Maastricht University Medical Center+, Maastricht, The Netherlands \\ ${ }^{\mathrm{d}}$ Department of Molecular Genetics, CARIM School for Cardiovascular Diseases, Maastricht University Medical Center+, Maastricht, The Netherlands
}

\section{A R T I C L E I N F O}

Article history:

Received 8 May 2011

Revised 7 October 2011

Accepted 8 November 2011

Available online 21 November 2011

Edited by Laszlo Nagy

\section{Keywords:}

UCP3

ROS

Mitochondria

Mild uncoupling

Lipotoxicity

\begin{abstract}
A B S T R A C T
Uncoupling protein 3 (UCP3) may reduce mitochondrial ROS production, and thereby protect against mitochondrial dysfunction in skeletal muscle. UCP3 has been suggested to specifically fulfill this role under high-fat conditions. Here we show that UCP3 knockout mice indeed have elevated mitochondrial ROS production after short-term (8 weeks) high-fat feeding. After 26 weeks of high-fat feeding, UCP3 knockout mice exhibited reduced mitochondrial function as measured ex vivo in isolated mitochondria. In conclusion, these data suggest that UCP3 may have a role in the protection of mitochondria against lipid-induced mitochondrial dysfunction, but only after long-term exposure to high-fat.
\end{abstract}

๑ 2011 Federation of European Biochemical Societies. Published by Elsevier B.V. All rights reserved.

\section{Introduction}

Uncoupling protein 3 (UCP3), which is mainly present in skeletal muscle $[1,2]$, has been suggested to play a role in fatty acid metabolism. Several recent hypotheses suppose a protective role for the protein against (lipid-induced) mitochondrial dysfunction or oxidative stress [3-5], by facilitating transport of fatty acid anions [3] or fatty acid hydroperoxides [4] across the inner mitochondrial membrane to the cytoplasm, or by directly attenuating reactive oxygen species (ROS) production [5]. In response to high-fat feeding, UCP3 overexpressing (UCP3Tg) mice show increased oxygen consumption [6], reduced body weight gain [7] and decreased accumulation of intramyocellular lipids (IMCL) [8] compared to WT control mice as well as protection against fatinduced insulin resistance [9]. In contrast, high-fat feeding in

Abbreviations: ROS, reactive oxygen species; UCP, uncoupling protein; ESR, electron spin resonance; UCP3 ${ }^{-1-}$, UCP3 knockout; WT, Wildtype; BSA, bovine serum albumin; DMPO, 5,5-dimethyl-1-pyrolline $\mathrm{N}$-oxide; FCCP, $p$-trifluoromethoxy carbonyl cyanide phenylhydrazone

* Corresponding author. Address: Department of Human Biology, NUTRIM School for Nutrition, Toxicology and Metabolism, Maastricht University Medical Center+, P.O. Box 616, 6200 MD Maastricht, The Netherlands. Fax: +31 433670976.

E-mail address: p.schrauwen@maastrichtuniversity.nl (P. Schrauwen).
UCP3 knockout (UCP3-1- $)$ animals resulted in increased accumulation of IMCL [8], increased plasma free fatty acids and a tendency to increased body weight [10] compared to wildtype (WT) control animals. Taken together, these findings indicate that UCP3 may indeed affect fatty acid metabolism.

In this context, we recently compared isolated skeletal muscle mitochondria from $\mathrm{UCP}^{-1-}$ and WT mice and examined the role of UCP3 in maintaining mitochondrial oxidative capacity under conditions of acute fatty acid exposure. Although the presence of fatty acids led to diminished maximal mitochondrial oxidative capacity, the absence of UCP3 did not aggravate the inhibitory effect of fatty acids on maximal oxidative capacity [11]. Additionally, no differences between genotypes were found in the fatty acid-induced decrease in membrane integrity or in basal lipid (per)oxidation products, indicating similar mitochondrial damage between UCP3 ${ }^{-1-}$ and WT animals.

Although these results do not fit a role for UCP3 in preserving mitochondrial functional capacity, it should be noted that these results were obtained upon acute exposure of isolated mitochondria to high levels of fatty acids. This hampers the extrapolation of the results from this in vitro approach to the in vivo situation, when the mitochondria are chronically exposed to fatty acids. In this context it is interesting to note that several studies indicate that 
prolonged high-fat feeding - in contrast to short-term high-fat feeding - in rodents results in mitochondrial dysfunction (reviewed in [12]). Thus, Bonnard et al. [13] showed that one month of high-fat/high-sucrose feeding in mice induced glucose intolerance, without affecting mitochondrial function, while extending the dietary intervention up to 4 months did result in altered skeletal muscle mitochondrial biogenesis, - morphology and - function. These authors suggested that elevated reactive oxygen species (ROS) production was responsible for the high-fat diet-induced reduction in mitochondrial function. Although increased levels of UCP3 mRNA upon the prolonged dietary intervention were reported, the role of UCP3 in the enhanced oxidative stress and decreased mitochondrial function was not examined. Taken together, it is likely that long-term exposure to fatty acids is necessary before the putative protective effect(s) of UCP3 on skeletal muscle mitochondria become evident.

So far only one study [14] has examined the effects of short- and long-term high-fat feeding (1, 2, 3, 4 and 8 months) in $\mathrm{UCP}^{-1-}$ and WT mice. Importantly, this study focused on intracellular lipid levels and insulin sensitivity rather than on mitochondrial functional capacity. Consequently, the significance of UCP3 in relation to skeletal muscle mitochondrial function and/or ROS production upon long-term exposure to a high-fat diet remains unclear.

In the present study, we therefore provided $\mathrm{UCP}^{-1-}$ and WT control mice to 8 or 26 weeks chow versus high-fat diet and subsequently assessed mitochondrial functional capacity by highresolution respirometry and mitochondrial ROS production by electron spin resonance (ESR) spectroscopy. We hypothesized that mitochondria from UCP3 ${ }^{-1-}$ mice would display elevated ROS production and decreased mitochondrial oxidative capacity, and that these effects would specifically become apparent upon long-term high-fat feeding.

\section{Materials and methods}

\subsection{Animals}

Male C57Bl/6 WT and UCP3 ${ }^{-1-}$ mice (backcrossed 10 generations onto a $\mathrm{C} 57 \mathrm{Bl} / 6$ background) were used. The creation of $\mathrm{UCP}^{-1-}$ mice has been described before [15]. At $10-15$ weeks of age, mice were randomly assigned to an 8-week 45 energy\% high-fat dietary intervention (HF-diet; D01060502, Research Diets, New Brunswick, USA; containing 35 E\% carbohydrates, 20 E\% protein and $45 \mathrm{E} \%$ fat), or maintained on standard laboratory chow diet (Sniff R/M H chow, Sniff spezialdiäten, Soest, Germany; containing $58 \mathrm{E} \%$ carbohydrates, $33 \mathrm{E} \%$ protein and $9 \mathrm{E} \% \mathrm{fat}$ ) for a similar period. In a second experiment, a separate group of animals (10-15 weeks of age) was randomly assigned to a 26-week dietary intervention with the same high-fat or chow diet. Animals were housed individually in a controlled environment $\left(21-22^{\circ} \mathrm{C}\right)$ with a $12: 12$ h light-dark cycle (light from 0700 to $1900 \mathrm{~h}$ ) and unlimited access to food and tap water. Body weights were recorded at the end of dietary intervention. All experiments were approved by the Animal Care and Use committee of Maastricht University and complied with principles of laboratory animal care.

\subsection{Tissue collection}

At the end of the dietary intervention, animals were sedated by a mixture of $79 \% \mathrm{CO}_{2}$ and $21 \% \mathrm{O}_{2}$ and sacrificed by decapitation. Hind limb skeletal muscle $(\sim 2.0 \mathrm{~g})$ was rapidly dissected and transferred into ice-cold mitochondrial isolation buffer containing $100 \mathrm{mM}$ sucrose, $50 \mathrm{mM} \mathrm{KCL}, 20 \mathrm{mM} \mathrm{K}{ }^{+}$-TES, $1 \mathrm{mM}$ EDTA, and $0.2 \%$ $(\mathrm{w} / \mathrm{v})$ fatty acid free bovine serum albumin (BSA). Tissue was used immediately for fresh isolation of skeletal muscle mitochondria, except for both tibialis anterior muscles that were frozen in liquid nitrogen and stored at $-80{ }^{\circ} \mathrm{C}$ until further analysis.

\subsection{UCP3 protein levels}

Protein expression levels of UCP3 were determined by western blotting in tibialis anterior muscle tissue homogenates of 8 weeks chow fed $\mathrm{UCP}^{-1-}$ and WT mice to confirm genotype. Densitometric analysis of Instant Blue staining (Expedeon, Cambridge, UK) was used to quantify the total protein content of every sample. Western blotting was performed using $13 \%$ polyacrylamide SDS-gels as described before $[2,16]$. Rabbit polyclonal antibody detecting UCP3 (code 1338 , kindly provided by LJ Slieker, Eli Lilly) was used. The UCP3 protein band was visualized by chemiluminescence and analyzed by densitometry using Image Master (Pharmacia Biotech, Roosendaal, the Netherlands). Blots were loaded with similar amounts of WT and UCP3 $3^{-1-}$ samples per blot and intensity was expressed in arbitrary units.

\subsection{Mitochondrial isolation}

Skeletal muscle mitochondria were isolated as previously described $[17,18]$. Briefly, tissue was finely minced with scissors and a mechanical potter homogenizer in the presence of $8.4 \mathrm{U} / \mathrm{g}$ muscle proteinase (Subtilisin, Sigma-Aldrich, St. Louis, MO, USA). The mixture was then centrifuged at $8500 \times \mathrm{g}$ for $10 \mathrm{~min}$ at $4^{\circ} \mathrm{C}$. Remaining pellets were resuspended in isolation buffer, homogenized by hand, using a Potter homogenizer, and centrifuged at $800 \times \mathrm{g}$ for $10 \mathrm{~min}$ at $4^{\circ} \mathrm{C}$. Supernatants were then centrifuged at $8500 \times \mathrm{g}$ for $10 \mathrm{~min}$ at $4{ }^{\circ} \mathrm{C}$. The final resulting mitochondrial pellets were gently resuspended by hand-homogenization in a small glass homogenizer. Mitochondrial protein concentration was determined using fluorescamine (Fluram ${ }^{\circledR}$, Fluka, Zwijndrecht, the Netherlands) with BSA as a standard.

Freshly isolated mitochondria were used immediately for analyses of ROS production and mitochondrial function.

\subsection{ROS production}

Mitochondrial superoxide anion radical production by freshly isolated mitochondria was measured as described earlier using Xband electron spin resonance (ESR) spectroscopy (Bruker EMX 1273 ) in combination with a spin trapping technique [17]. Briefly, a combination of malate $(3 \mathrm{mM})$, glutamate $(5 \mathrm{mM})$ and succinate ( $5 \mathrm{mM}$ ) was added in an attempt to mimic formation of intermediates of the citric acid cycle as is the case in vivo. Furthermore, activated charcoal purified 5,5-dimethyl-1-pyrolline $\mathrm{N}$-oxide (DMPO) (100 mM; Sigma-Aldrich, St Louis, MO, USA) was added as spin trapping agent. Superoxide anion radical derived DMPO-OH' signals, previously shown to be completely inhibited by superoxide dismutase [17], were measured using the WIN-EPR spectrum qualification program (version 2.11, Bruker, Rheinstetten, Germany). Quantification of the spectra by peak height measurements was performed by summation of four peaks of the DMPO-OH' signal. Values are expressed as percentage of the radical signal intensity of the WT mice.

\subsection{Mitochondrial function}

Mitochondrial respiration rates, as a measure of mitochondrial function, were determined as described earlier [17] using a twochambered Oxygraph (Oroboros ${ }^{\circledR}$ Instruments, Innsbruck, Austria). Pyruvate $(5 \mathrm{mM})$ was used as a carbohydrate-derived substrate while palmitoyl-CoA $(2 \mathrm{mM})+\mathrm{L}$-carnitine $(50 \mu \mathrm{M})$ was used as a fatty acid substrate. All conditions were in the presence of malate $(3 \mathrm{mM})$ as this was present in the respiration buffer. State 3 respiration was initiated by addition of $\operatorname{ADP}(450 \mu \mathrm{M})$ whereas state 40 respiration was 
Table 1

Body weights of mice after 8- and 26-week dietary intervention.

\begin{tabular}{lll}
\hline Body weight $(\mathrm{g})$ & WT & $\mathrm{UCP}^{-1-}$ \\
\hline 8 Weeks chow diet & $29.2 \pm 0.7$ & $27.3 \pm 0.7$ \\
8 Weeks high-fat diet & $29.0 \pm 1.7$ & $30.6 \pm 0.8$ \\
26 Weeks chow diet & $31.2 \pm 0.4$ & $31.5 \pm 1.0$ \\
26 Weeks high-fat diet & $36.8 \pm 1.8$ & $44.6 \pm 2.8^{1}$ \\
\hline
\end{tabular}

Values are expressed as mean \pm SEM.

${ }^{1}$ Compared to WT, $P=0.07(n=7-11)$.

measured in the presence of the ATP-synthase inhibitor oligomycin $(1 \mu \mathrm{g} / \mathrm{ml})$. Maximal capacity of the electron transport chain (state $\mathrm{U})$ was determined upon titration with the chemical uncoupler carbonyl cyanide $p$-trifluoromethoxyphenylhydrazone (FCCP).

\subsection{Statistical analyses}

Statistical analyses were performed using SPSS for Windows 15.0 software (SPSS Inc., Chicago, IL, USA). All data are presented as means \pm S.E.M. Unpaired $t$-test was performed with statistically significance threshold set at $P=0.05$.

\section{Results}

\subsection{UCP3 protein expression and body weight}

UCP3 protein was undetectably low in $\mathrm{UCP}^{-1-}$ animals confirming their genotype. In WT animals, UCP3 protein levels were: $1.0 \pm 0.3 \mathrm{AU}$ after 8 weeks of chow, $1.5 \pm 0.3 \mathrm{AU}$ after 8 weeks high-fat, $0.10 \pm 0.06 \mathrm{AU}$ after 26 weeks chow and $0.86 \pm 0.46 \mathrm{AU}$ after 26 weeks high-fat feeding.

No differences in body weight were detected between genotype after either 8 weeks of chow or high-fat feeding (Table 1). Body weight was also similar between genotypes after 26 weeks of chow feeding. However, UCP3 ${ }^{-1-}$ animals did show a tendency to higher body weight after 26 weeks of high-fat feeding, when compared to WT.

\subsection{Effect of UCP3 on mitochondrial metabolism: 8 Weeks chow diet}

Mitochondrial superoxide anion radical production, determined under state 40 conditions, was similar in both genotypes upon 8 weeks of chow diet feeding (Table 2). In accordance with mitochondrial ROS production, also mitochondrial function was similar between both genotypes either when fuelled by pyruvate or by palmitoyl-CoA + L-carnitine, i.e. both ADP-stimulated respiration and maximally uncoupled respiration rates were similar (Table 2 ). Despite the putative role of UCP3 in mediating mitochondrial proton leak, state 40 respiration rates were similar in $\mathrm{UCP}^{-1-}$ and WT mice (Table 2).

\subsection{Effect of UCP3 on mitochondrial metabolism: 8 Weeks high-fat diet}

After 8 weeks of high-fat feeding, the superoxide production was higher in $\mathrm{UCP}^{-l-}$ animals when compared to WT mice (Fig. 1a, $P<0.05$ ). However, this did not result in altered mitochondrial function between the genotypes, neither on pyruvate (Fig. 1b) nor on palmitoyl-CoA + L-carnitine (Fig. 1c). Also, mitochondrial uncoupling was not affected by genotype, on either of the substrates (Fig. 1d, e).

To exclude the possibility that the dietary intervention would be too short to reveal the putative protective effect of UCP3 on mitochondrial function, we also subjected the mice to a more prolonged, i.e., 26-week dietary intervention. Again, body weight was not different after 26 weeks of chow diet in $\mathrm{UCP}^{-1-}$ versus WT mice. Upon 26 weeks of high-fat diet feeding, the UCP3 ${ }^{-1-}$ mice tended to have higher body weights as compared to the WT $(P=0.07$, Table 1$)$.

\subsection{Effect of UCP3 on mitochondrial metabolism: 26 Weeks chow diet}

Upon 26 weeks of chow diet (Fig. 2a), mitochondrial superoxide anion radical production was higher in $\mathrm{UCP}^{-1-}$ versus WT animals $(P<0.01)$. Again, this did not result in differences in mitochondrial function between the genotypes, neither on pyruvate (Fig. $2 b$ ) nor on palmitoyl-CoA + L-carnitine (Fig. 2c) Also state 4o respiration levels - indicative of mitochondrial uncoupling - were not different between UCP3 ${ }^{-1-}$ versus WT mice (pyruvate: Fig. $2 \mathrm{~d}$, and palmitoyl-CoA + L-carnitine: Fig. 2e).

\subsection{Effect of UCP3 on mitochondrial metabolism: 26 Weeks high-fat diet}

Unexpectedly, after 26 weeks of the high-fat diet mitochondrial superoxide anion radical production was similar in both genotypes (Fig. 3a). At this stage UCP3 ${ }^{-1-}$ mice showed a significantly lower mitochondrial capacity as compared to WT animals when fuelled by pyruvate. Thus, both ADP-stimulated respiration $(P<0.01)$ and maximal mitochondrial capacity $(P<0.01)$ were reduced in $\mathrm{UCP}^{-l-}$ mice (Fig. 3b). Also upon palmitoyl-CoA $+\mathrm{L}$-carnitine, the ADP-stimulated respiration was significantly lower in $\mathrm{UCP}^{-1-}$ mice as compared to WT animals (Fig. 3c; $P<0.05$ ), while the reduction in maximal mitochondrial capacity did not reach statistical significance (Fig. 3c). Finally, state 40 respiration was significantly lower in $\mathrm{UCP}^{-1-}$ versus WT mice, both on pyruvate

Table 2

Effect of 8 weeks chow feeding on skeletal muscle mitochondrial metabolism of WT and UCP3 ${ }^{-1-}$ mice.

\begin{tabular}{|c|c|c|}
\hline Body weight $(\mathrm{g})$ & WT & $\mathrm{UCP}^{-1-}$ \\
\hline \multicolumn{3}{|l|}{ ROS production (\% of WT radical signal intensity) } \\
\hline Superoxide anion production & $100 \pm 8.3$ & $89.9 \pm 3.8$ \\
\hline \multicolumn{3}{|l|}{ ADP-stimulated respiratory rate $\left(\mathrm{nmol} \mathrm{O}_{2} / \mathrm{mg} / \mathrm{min}\right)$} \\
\hline Glycolytic substrate (pyruvate) & $306.8 \pm 21.8$ & $323.4 \pm 57.0$ \\
\hline Fatty acid substrate (palmitoyl-CoA + L-carnitine) & $92.1 \pm 11.8$ & $80.2 \pm 8.2$ \\
\hline \multicolumn{3}{|c|}{ Maximal electron transport chain capacity $\left(\mathrm{nmol} \mathrm{O}_{2} / \mathrm{mg} / \mathrm{min}\right)$} \\
\hline Glycolytic substrate (pyruvate) & $413.1 \pm 16.2$ & $443.4 \pm 46.6$ \\
\hline Fatty acid substrate (palmitoyl-CoA + L-carnitine) & $129.4 \pm 18.3$ & $115.5 \pm 12.3$ \\
\hline \multicolumn{3}{|l|}{ State 4 uncoupled respiratory rate $\left(\mathrm{nmol} \mathrm{O}_{2} / \mathrm{mg} / \mathrm{min}\right)$} \\
\hline Glycolytic substrate (pyruvate) & $17.5 \pm 1.5$ & $17.2 \pm 1.8$ \\
\hline Fatty acid substrate (palmitoyl-CoA + L-carnitine) & $16.7 \pm 2.8$ & $12.9 \pm 1.3$ \\
\hline
\end{tabular}

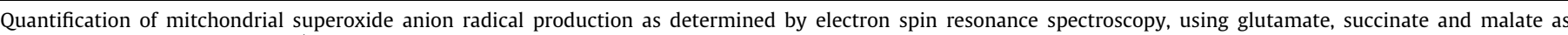

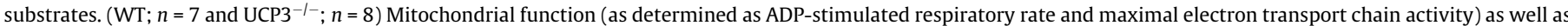

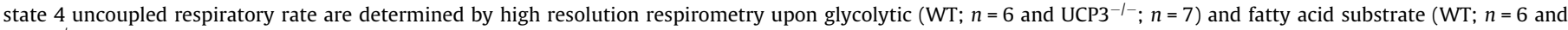
$\left.\mathrm{UCP}^{-1-} ; n=7\right)$. Values are expressed as mean \pm SEM. 


\section{(a) ROS production}

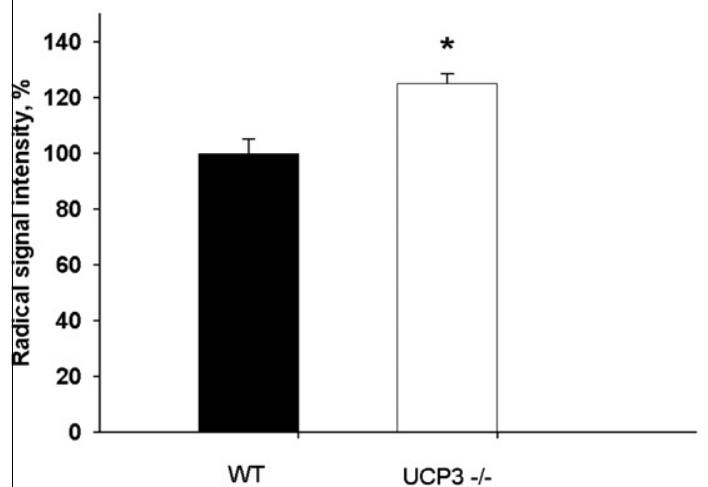

(b) Mitochondrial function - pyruvate

(c) Mitochondrial function - palmitoyl-CoA + carnitine
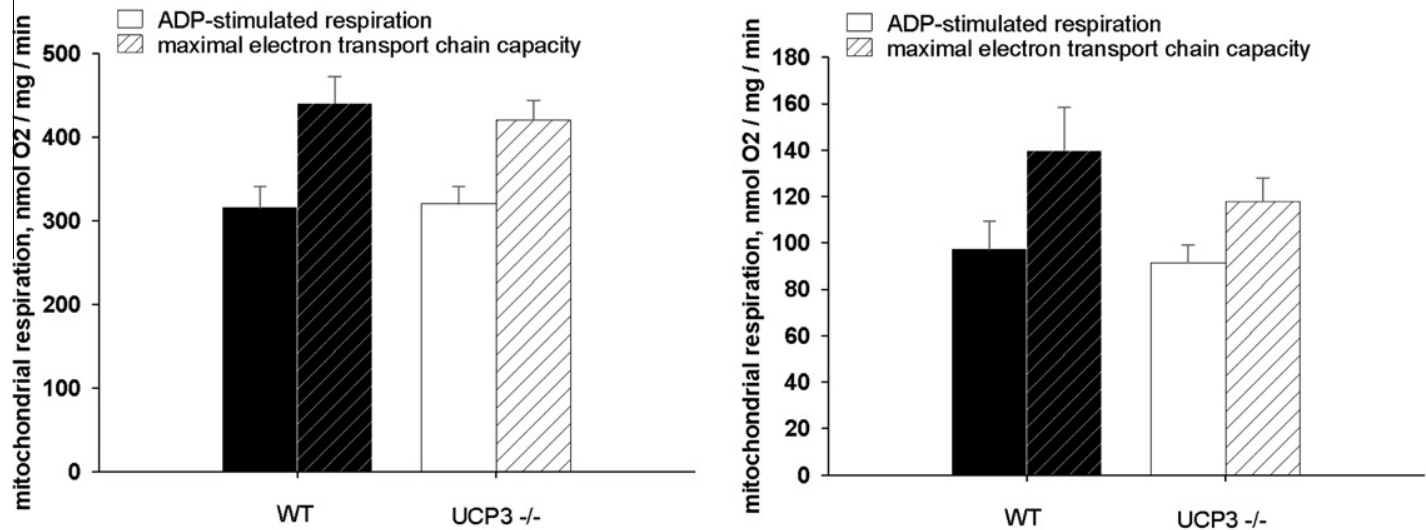

(d) Uncoupling - pyruvate

(e) Uncoupling - palmitoyl-CoA + carnitine
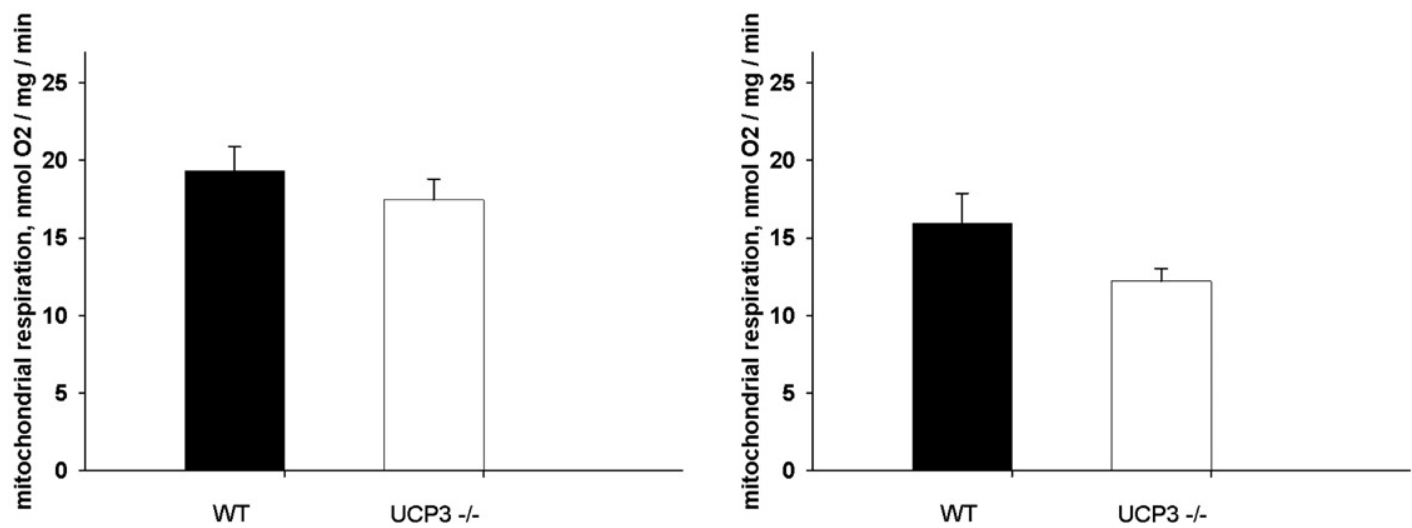

Fig. 1. Effect of 8 weeks high-fat feeding on skeletal muscle mitochondrial metabolism of WT and UCP ${ }^{-1-}$ mice. (a) Superoxide anion radical production measurements were performed using malate + glutamate + succinate as substrates. The radical signal intensity of the WT mice is set to $100 \%$. (WT; $n=10$ and UCP3 $3^{-1-} ; n=9$ ). Mitochondrial function was assessed using both ADP-stimulated "state 3" respiratory rates (filled bars) as well as maximal capacity of the electron transport chain (or maximal uncoupled "state U" respiratory rates) (hatched bars) upon carbohydrate-derived (WT; $n=9$ and UCP3-l-; $n=7$ ) (b) and fatty acid (WT; $n=10$ and UCP3 $\left.{ }^{-l-} ; n=7\right)(\mathrm{c})$ substrates.

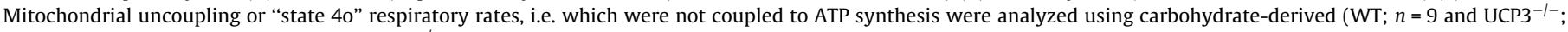
$n=7$ ) (d) and fatty acid (WT; $n=9$ and UCP3 ${ }^{-1-} ; n=7$ ) (e) substrates. Values are expressed as mean \pm SEM. ${ }^{*}-$ statistically significant different compared to WT, $P<0.05$.

$(P<0.001)$ and on palmitoyl-CoA + L-carnitine $(P<0.05)$, indicating lower proton leak in animals lacking UCP3 (Fig. 3d, e).

\section{Discussion}

In the present study we show that lack of UCP3 increases mitochondrial ROS production, as measured ex vivo in isolated mitochondria, although we only observed this after short-term high-fat or long-term chow feeding. Furthermore, we show that lack of UCP3 is associated with a reduced mitochondrial function both on pyruvate and palmitoyl-CoA $+{ }_{\mathrm{L}}$-carnitine, but only after long-term high-fat feeding. These data suggest that UCP3 exerts a mild effect in the protection of mitochondria against lipid-induced mitochondrial dysfunction, which only becomes apparent after long-term exposure to high-fat environments. 
(a) ROS production

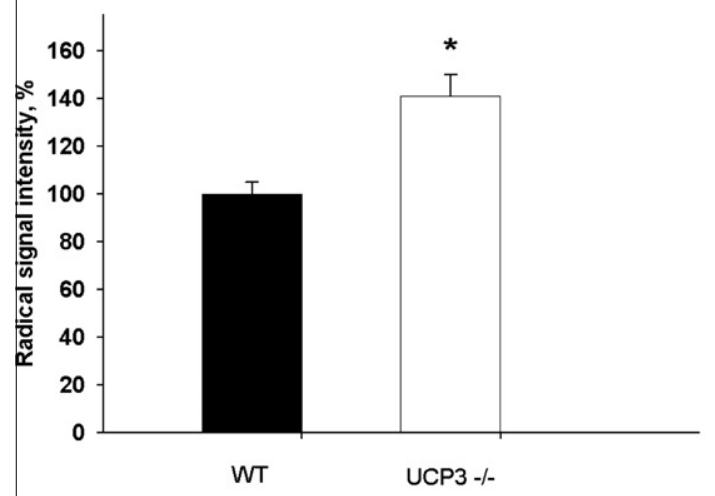

(b) Mitochondrial function - pyruvate

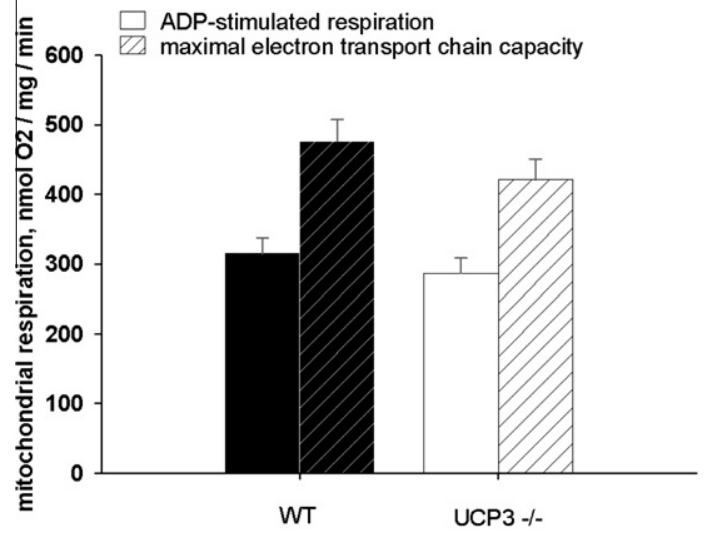

(d) Uncoupling - pyruvate

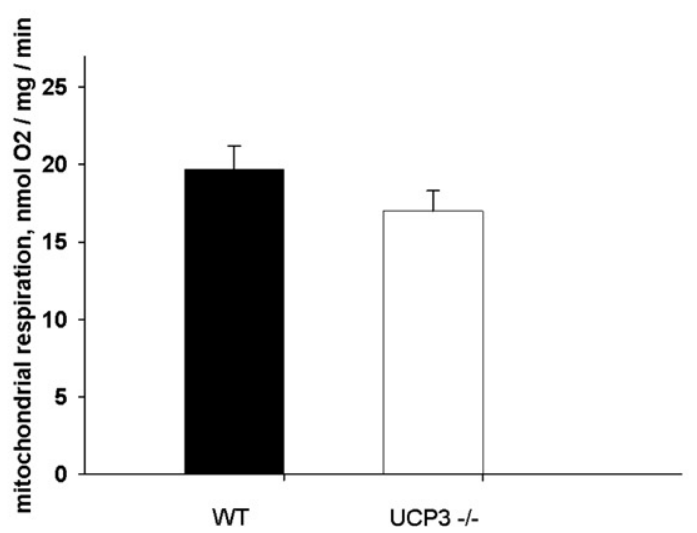

\section{(c) Mitochondrial function - palmitoyl-CoA + carnitine}

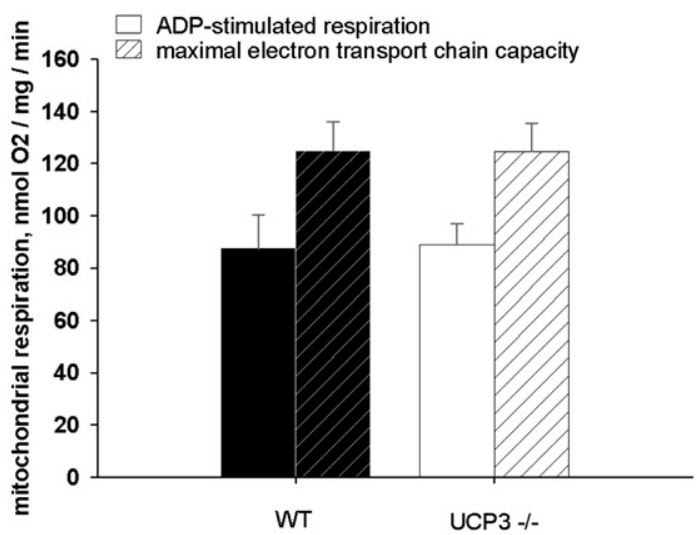

(e) Uncoupling - palmitoyl-CoA + carnitine

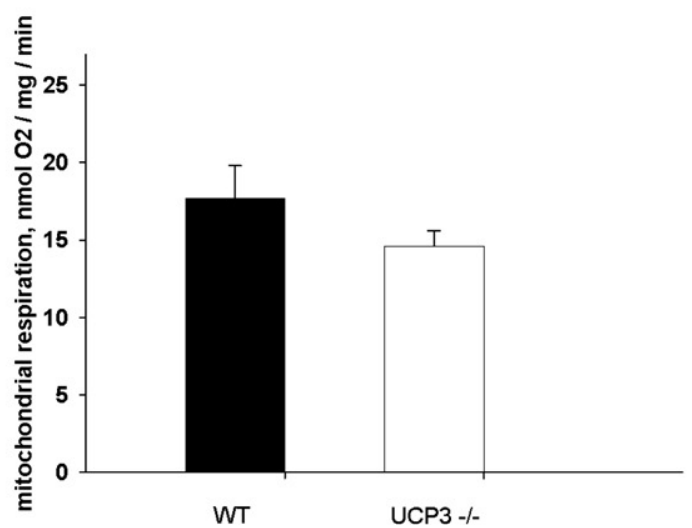

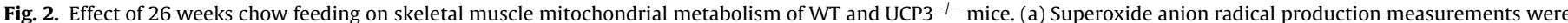

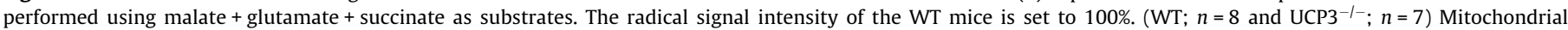

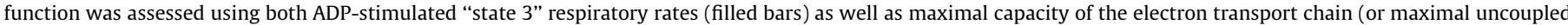

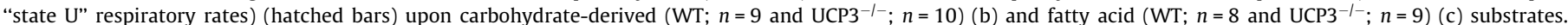

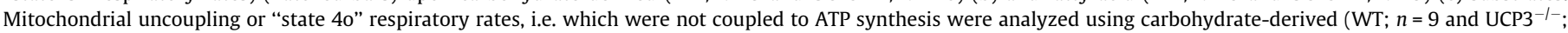

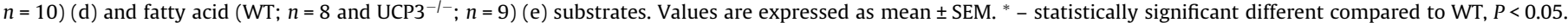

\subsection{Mitochondrial uncoupling}

UCP3, if operating as a genuine and thermogenic uncoupling protein, i.e., releasing energy as heat instead of ATP, has been suggested to affect body weight.

Interestingly, only after 26 weeks of high-fat feeding, UCP3 ${ }^{-1-}$ animals tended to have higher body weights. This is in agreement with previous reports that showed that long-term high-fat feeding (>8 weeks) [10] and not short-term high-fat or chow feeding $[8,10,15]$ resulted in a more pronounced increase in body weight in $\mathrm{UCP}^{-1-}$ animals when compared to WT. Additionally, the higher body weights in the $\mathrm{UCP}^{-1-}$ mice after 26 weeks of high-fat diet feeding were accompanied by higher coupling rates (i.e. lower state 40 respiration), which may suggest that effects of UCP3 on body weight become apparent after longterm high-fat feeding, perhaps because the effect of UCP3 on 


\section{(a) ROS production}

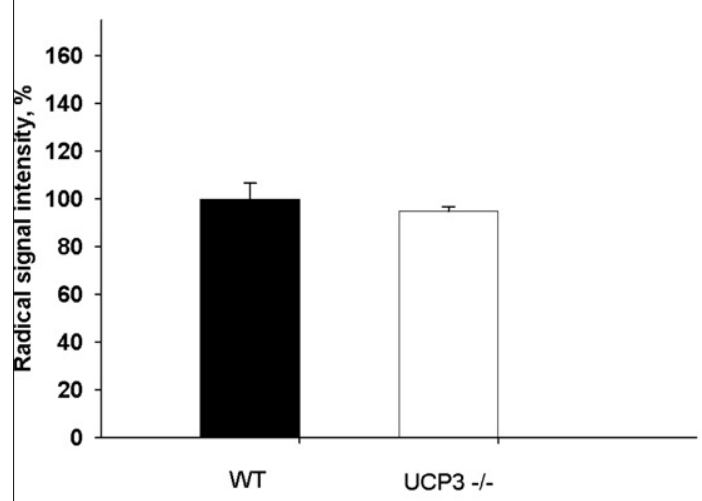

(b) Mitochondrial function - pyruvate

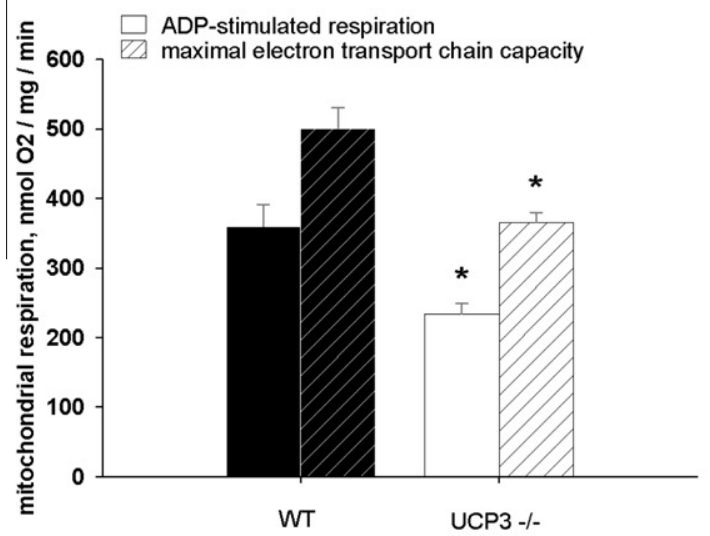

(d) Uncoupling - pyruvate

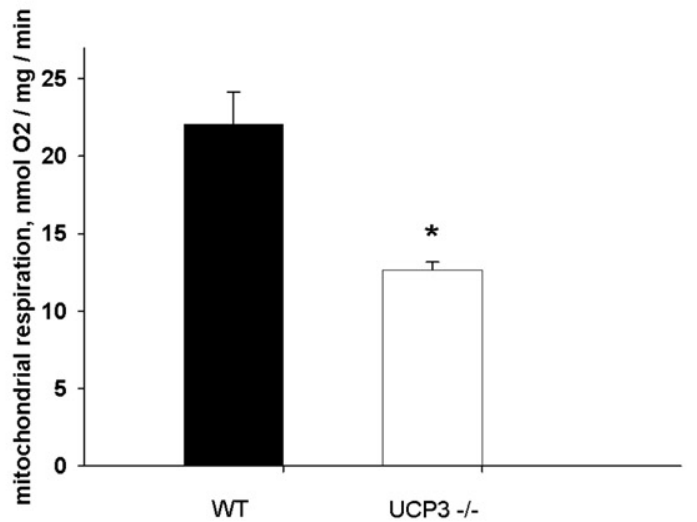

(c) Mitochondrial function - palmitoyl-CoA + carnitine

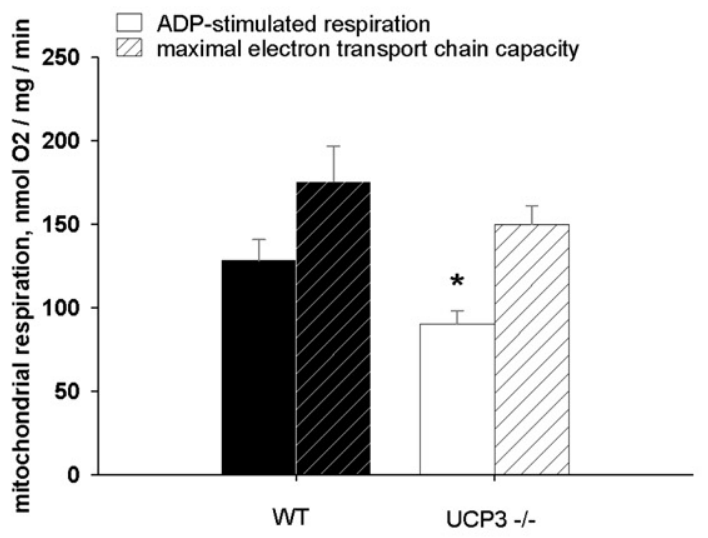

(e) Uncoupling - palmitoyl-CoA + carnitine

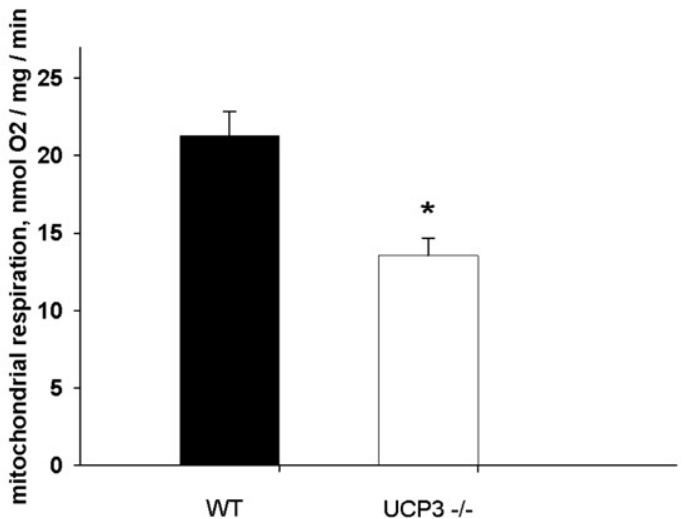

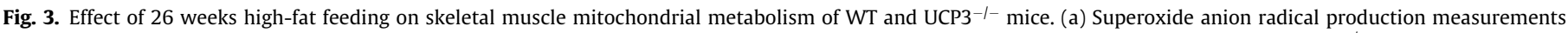

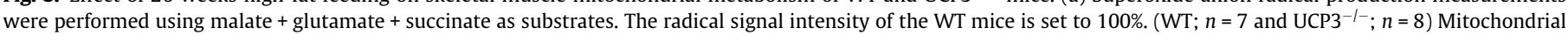

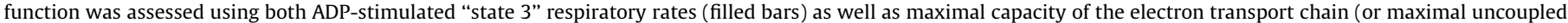

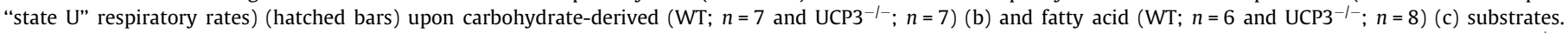

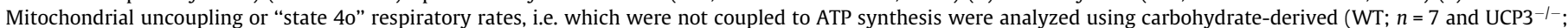

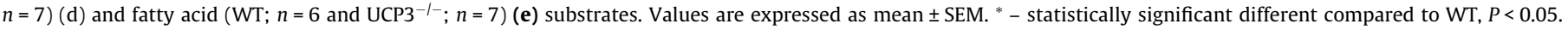

uncoupling is so small that only long-term effects on body weight can be detected.

\subsection{UCP3 and mitochondrial ROS production}

UCP3 is suggested to modulate ROS production by reducing the mitochondrial proton gradient and it can be hypothesized that this occurs especially under conditions of high fatty acid availability $[19,20]$. Consistently, we here show higher ROS production in the
$\mathrm{UCP}^{-1-}$ mice compared to the WT mice after 8 weeks of a highfat diet, but not after 8 weeks of a chow diet. Using electron spin resonance spectroscopy, our data adds to studies that showed similar ROS related effects of UCP3 using indirect measurements [10,21-23].

Interestingly, higher ROS production was also detected in $\mathrm{UCP}^{-1-}$ mice after 26 weeks of chow diet, which is in line with our previous study in which we showed that 75 week-old UCP3Tg mice were protected against age-induced increases in ROS 
production, whereas ROS production at younger age was similar to WT mice [17]. Although speculative, these results may suggest that the higher levels of ROS in UCP3 ${ }^{-1-}$ mitochondria after 26 weeks of chow diet may represent an exaggerated age-induced induction of ROS in UCP $3^{-1-}$. The contrary finding that lack of UCP3 had no effect on ROS production after 26 weeks of high-fat feeding, might be explained by reduced mitochondrial function (see below).

\subsection{Mitochondrial function}

UCP3 has been implicated in the protection against (lipidinduced) mitochondrial dysfunction or oxidative stress [3-5]. In a recent study [11] we found that acutely exposing isolated skeletal muscle mitochondria to fatty acids reduced the maximal mitochondrial oxidative capacity, but this decrease in mitochondrial function was similar between WT and UCP3 ${ }^{-1-}$ animals. However, in vivo the body is exposed to high levels of fatty acids and ROS for a life-long period, and UCP3 may still function to prevent deterioration of mitochondrial function in time. We therefore examined the role of UCP3 in maintaining mitochondrial capacity upon prolonged in vivo exposure to high-fat diets. In general, after a relatively short period of dietary intervention ( 8 weeks) we did not find a relation between the lack of UCP3 and the functional capacity of the mitochondria, neither under normal chow-fed conditions nor after 8 weeks of high-fat feeding, which is consistent with our acute experiments. However, 8 weeks of high-fat diet might still be too short to elicit mitochondrial dysfunction and long-term high-fat interventions might be needed to decrease mitochondrial function [13]. Indeed, after 26 weeks of high-fat diet feeding mitochondrial function was lower in $\mathrm{UCP}^{-1-}$ mice as compared to WTs. The lower mitochondrial function in the UCP3 ${ }^{-1-}$ animals appears in line with data from Seifert et al. [24] who showed that under chow fed conditions, UCP3 ${ }^{-1-}$ and WT mice have a similar fatty acid oxidation, whereas after overnight fasting, i.e., upon high levels of fatty acids, UCP3 was found obligatory to augment palmitoyl-carnitine oxidation rate. Remarkably however, whereas the 26 weeks of high-fat feeding is the only condition in which mitochondrial function fuelled by both pyruvate and fatty acids is blunted in UCP3 ${ }^{-1-}$ mice, this is also the condition in which unexpectedly no effects on ROS production were found. Possibly the lower mitochondrial respiration in this group underlies the blunted ROS production as measured ex vivo in isolated mitochondria, although no clear correlation can be made as oxygen consumption and ROS production measurements were performed using different substrates. Alternatively, the changes in mitochondrial function observed in UCP3 ${ }^{-1-}$ mice are not causally related to mitochondrial ROS production.

In summary, we report that UCP3 may have direct effects on mitochondrial ROS production and can protect mitochondria against high-fat diet induced reduction in mitochondrial function, but only after prolonged consumption of high-fat diets. Interestingly, UCP3 levels are reduced by $50 \%$ in human patients with type 2 diabetes mellitus and these patients are also characterized by reduced mitochondrial function and elevated oxidative stress $[25,26]$. As also type 2 diabetes is a disease, which takes years to fully develop, it is tempting to speculate that UCP3 may also in humans play a role in the regulation of ROS production and the prevention of the long-term deterioration of mitochondrial function. Further research is needed to investigate this suggestion and to examine the exact mechanisms by which UCP3 may affect ROS and/or mitochondrial function.

\section{Acknowledgements}

We thank Dr. Mary-Ellen Harper for kindly providing us with the $\mathrm{UCP}^{-1-}$ mice. This study was supported by The Netherlands
Organization for Health Research \& Development (ZonMw) (Grant No. 9120.6050).

\section{References}

[1] Vidal-Puig, A., Solanes, G., Grujic, D., Flier, J.S. and Lowell, B.B. (1997) UCP3: an uncoupling protein homologue expressed preferentially and abundantly in skeletal muscle and brown adipose tissue. Biochem Biophys Res Commun 235, 79-82.

[2] Hoeks, J., Hesselink, M.K., van Bilsen, M., Schaart, G., van der Vusse, G.J., Saris, W.H. and Schrauwen, P. (2003) Differential response of UCP3 to medium versus long chain triacylglycerols; manifestation of a functional adaptation. FEBS Lett 555, 631-637.

[3] Schrauwen, P., Saris, W.H. and Hesselink, M.K. (2001) An alternative function for human uncoupling protein 3: protection of mitochondria against accumulation of non-esterified fatty acids inside the mitochondrial matrix. Faseb J 15, 2497-2502.

[4] Lombardi, A. et al. (2010) UCP3 translocates lipid hydroperoxide and mediates lipid hydroperoxide-dependent mitochondrial uncoupling. J Biol Chem 285 16599-16605.

[5] Brand, M.D. et al. (2004) Mitochondrial superoxide and aging: uncouplingprotein activity and superoxide production. Biochem Soc Symp 203, 13.

[6] Son, C., Hosoda, K., Ishihara, K., Bevilacqua, L., Masuzaki, H., Fushiki, T., Harper M.E. and Nakao, K. (2004) Reduction of diet-induced obesity in transgenic mice overexpressing uncoupling protein 3 in skeletal muscle. Diabetologia 47, 47-54.

[7] Clapham, J.C. et al. (2000) Mice overexpressing human uncoupling protein-3 in skeletal muscle are hyperphagic and lean. Nature 406, 415-418.

[8] Costford, S.R., Chaudhry, S.N., Salkhordeh, M. and Harper, M.E. (2006) Effects of the presence, absence, and overexpression of uncoupling protein-3 on adiposity and fuel metabolism in congenic mice. Am J Physiol Endocrinol Metab 290, E1304-E1312.

[9] Choi, C.S. et al. (2007) Overexpression of uncoupling protein 3 in skeletal muscle protects against fat-induced insulin resistance. J Clin Invest 117, 19952003.

[10] Vidal-Puig, A.J. et al. (2000) Energy metabolism in uncoupling protein 3 gene knockout mice. J Biol Chem 275, 16258-16266.

[11] Nabben, M., Shabalina, I.G., Moonen-Kornips, E., Van Beurden, D., Cannon, B. Schrauwen, P., Nedergaard, J. and Hoeks, J. (2011) Uncoupled respiration, ROS production, acute lipotoxicity and oxidative damage in isolated mitochondria from UCP3-ablated mice. Biochem Biophys Acta 1807, 1095-1105.

[12] Schrauwen, P., Schrauwen-Hinderling, V., Hoeks, J. and Hesselink, M.K. (2010) Mitochondrial dysfunction and lipotoxicity. Biochim Biophys Acta 1801, 266271.

[13] Bonnard, C., Durand, A., Peyrol, S., Chanseaume, E., Chauvin, M.A., Morio, B. Vidal, H. and Rieusset, J. (2008) Mitochondrial dysfunction results from oxidative stress in the skeletal muscle of diet-induced insulin-resistant mice. J Clin Invest 118, 789-800.

[14] Costford, S.R., Chaudhry, S.N., Crawford, S.A., Salkhordeh, M. and Harper, M.E. (2008) Long-term high-fat feeding induces greater fat storage in mice lacking UCP3. Am J Physiol Endocrinol Metab 295, E1018-E1024.

[15] Gong, D.W. et al. (2000) Lack of obesity and normal response to fasting and thyroid hormone in mice lacking uncoupling protein-3. J Biol Chem 275, 16251-16257.

[16] Mensink, M., Hesselink, M.K., Russell, A.P., Schaart, G., Sels, J.P. and Schrauwen, P. (2007) Improved skeletal muscle oxidative enzyme activity and restoration of PGC-1 alpha and PPAR beta/delta gene expression upon rosiglitazone treatment in obese patients with type 2 diabetes mellitus. Int J Obes (Lond) 31 , 1302-1310.

[17] Nabben, M., Hoeks, J., Briede, J.J., Glatz, J.F., Moonen-Kornips, E., Hesselink M.K. and Schrauwen, P. (2008) The effect of UCP3 overexpression on mitochondrial ROS production in skeletal muscle of young versus aged mice. FEBS Lett 582, 4147-4152.

[18] Shabalina, I.G., Hoeks, J., Kramarova, T.V., Schrauwen, P., Cannon, B. and Nedergaard, J. (2010) Cold tolerance of UCP1-ablated mice. A skeletal muscle mitochondria switch toward lipid oxidation with marked UCP3 up-regulation not associated with increased basal, fatty acid- or ROS-induced uncoupling or enhanced GDP effects. Biochim Biophys Acta 1797, 968-980.

[19] Catala-Niell, A., Estrany, M.E., Proenza, A.M., Gianotti, M. and Llado, I. (2008) Skeletal muscle and liver oxidative metabolism in response to a voluntary isocaloric intake of a high fat diet in male and female rats. Cell Physio Biochem 22, 327-336.

[20] Nabben, M. and Hoeks, J. (2008) Mitochondrial uncoupling protein 3 and its role in cardiac- and skeletal muscle metabolism. Physiol Behav 94, 259-269.

[21] MacLellan, J.D., Gerrits, M.F., Gowing, A., Smith, P.J., Wheeler, M.B. and Harper M.E. (2005) Physiological increases in uncoupling protein 3 augment fatty acid oxidation and decrease reactive oxygen species production without uncoupling respiration in muscle cells. Diabetes 54, 2343-2350.

[22] Talbot, D.A. and Brand, M.D. (2005) Uncoupling protein 3 protects aconitase against inactivation in isolated skeletal muscle mitochondria. Biochim Biophys Acta 1709, 150-156.

[23] Brand, M.D., Pamplona, R., Portero-Otin, M., Requena, J.R., Roebuck, S.J., Buckingham, J.A., Clapham, J.C. and Cadenas, S. (2002). Oxidative damage and phospholipid fatty acyl composition in skeletal muscle mitochondria from 
mice underexpressing or overexpressing uncoupling protein 3. Biochem J Pt.Please provide complete details for the Ref. [23].

[24] Seifert, E.L., Bezaire, V., Estey, C. and Harper, M.E. (2008) Essential role for uncoupling protein-3 in mitochondrial adaptation to fasting but not in fatty acid oxidation or fatty acid anion export. J Biol Chem 283, 25124-25131.
[25] Lumini, J.A., Magalhaes, J., Oliveira, P.J. and Ascensao, A. (2008) Beneficial effects of exercise on muscle mitochondrial function in diabetes mellitus. Sports Med 38, 735-750.

[26] Schrauwen, P. and Hesselink, M.K. (2004) Oxidative capacity, lipotoxicity, and mitochondrial damage in type 2 diabetes. Diabetes 53, 1412-1417. 